\title{
Developing a learning management with local wisdom integration to improve reading and writing skills
}

\author{
Dhanita Doungwilai ${ }^{a^{*}}$ \\ Paiboon Limmanee ${ }^{b}$
}

Suggested Citation:

New Trends and Issues Proceedings on Humanities and Social

Sciences.

K

Abstract

L 
1. Introduction

2. The Purposes of the Research

3. Research Hypothesis

4. Methodology

4.1. Population and sample 
New Trends and Issues Proceedings on Humanities and Social Sciences.

\subsection{Research instruments}

- 
Table 2. Effectiveness index for learning achievement of the upper-primary students on the topic "A Tour in Mahasarakham" through the integration of reading and writing

Table 3. The comparison of reading and writing abilities of the upper-primary students before and after learning

iting was at the highest level (을 = 4.52).

\section{Discussion}




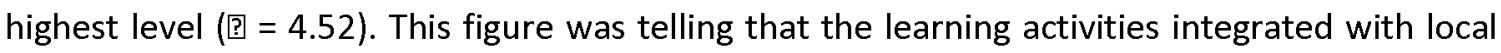

\section{Suggestions}

\subsection{Suggestions for implementation}

\subsection{Suggestions for future research}




\section{References}

The 5C skills to improve learning units and integrated learning instruction

$\mathrm{L} \quad$ The effects of arranging synectics activities in a Thai language class on creative writing of Prathomsuksa 2 students

$\mathrm{L}$

Effectiveness index calculation

The basic education core curriculum B.E. 2551 (A.D. 2008)

K

A construction of local-based content on "Chemicals in Local Communities".

The effects of the arrangement of learning activities for the Thai subject on reading and writing omission and replacement of vowels for Prathomsuksa 1 students through the use of mind mapping

Development of a local-based curriculum belonging to the Thai Division at Nonghaiwittaya on the topic "Phaya" for Mathayomsuksa 2 students

Introduction to research

Instructional design and integration 